\title{
Management of Velopharyngeal Insufficiency Using Double Opposing Z-Plasty in Patients Undergoing Primary Two-Flap Palatoplasty
}

\author{
Kyung Suk Koh, Sung Chan Kim, Tae Suk Oh \\ Department of Plastic Surgery, Asan Medical Center, University of Ulsan College of Medicine, Seoul, Korea
}

Background Velopharyngeal insufficiency (VPI) may persist after primary repair of the cleft palate, and surgical correction is necessary in many cases. The purpose of this study is to evaluate the effect of double opposing Z-plasty (DOZ) in cleft palate patients suffering from VPI after primary two-flap palatoplasty.

Methods Between March 1999 and August 2005, we identified 82 patients who underwent two-flap palatoplasty for cleft palate repair. After excluding the patients with congenital syndrome and mental retardation, 13 patients were included in the final study group. The average age of the patients who underwent DOZ at was 5 years and 1 month. Resonance, nasal emission, and articulation were evaluated by a speech pathologist. The velopharyngeal gaps were measured before and after surgery.

Results Six patients attained normal speech capabilities after DOZ. The hypernasality grade was significantly improved after surgery in all of the patients $(P=0.0015)$. Whereas nasal emission disappeared in 8 patients (61.5\%), it was diminished but still persisted in the remaining 5 patients. Articulation was improved in all of the cases. In two cases, the velopharyngeal gap was measured using a ruler. The gap decreased from 11.5 to $7 \mathrm{~mm}$ in one case, and from 12.5 to $8 \mathrm{~mm}$ in the second case.

Conclusions The use of DOZ as a surgical option to correct VPI has many advantages compared with other procedures. These include short surgery time, few troublesome complications, and no harmful effects on the dynamic physiological functioning of the pharynx. This study shows that DOZ can be another option for surgical treatment of patients with VPI after two-flap palatoplasty.

Keywords Velopharyngeal insufficiency / Cleft palate / Palate
Correspondence: Kyung Suk Koh Department of Plastic Surgery, Asan Medical Center, University of Ulsan College of Medicine, 88 Olympic-ro 43-gil, Songpa-gu, Seoul 138-736, Korea

Tel: +82-2-3010-3601

Fax: $+82-2-476-7471$

E-mail: kskoh@amc.seoul.kr

This article was presented at the 67 th Congress of The Korean Society of Plastic and Reconstructive Surgeons, and at the 12th Scientific Meeting of the Korean Cleft-Palate-Craniofacial Association, on November 19th, 2009 in Seoul, Korea

No potential conflict of interest relevant to this article was reported.

Received: 13 Nov 2012 • Revised: 9 Jan 2013 • Accepted: 15 Jan 2013

pISSN: 2234-6163 • elSSN: 2234-6171 • http://dx.doi.org/10.5999/aps.2013.40.2.97• Arch Plast Surg 2013;40:97-103

\section{INTRODUCTION}

The incidence of velopharyngeal insufficiency (VPI) after primary palatoplasty ranges from $5 \%$ to $36 \%$, making VPI a clinical challenge for plastic surgeons $[1,2]$. The surgical treatment choice for VPI remains controversial, with the best options including sphincter pharyngoplasty, posterior pharyngeal wall augmentation, pharyngeal flap surgery, and palatoplasty [3-6]. The most commonly used surgical technique to correct VPI has been the pharyngeal flap procedure, although this method may deform the normal anatomy and can cause various troublesome complications such as obstructive sleep apnea, snoring, mouth breathing, difficulty in clearing nasal secretion, and even hyponasal resonance [7-9]. 
Intraoral examination of patients suffering from VPI after primary palatal repair shows a malpositioned levator veli palatini muscle with a scarred palate, which gives the soft palate the appearance of being shortened and pulled anteriorly [9]. Based on these findings, double opposing Z-plasty (DOZ) can be an appropriate surgical technique to correct VPI caused by primary palatoplasty. Because the $\mathrm{DOZ}$ procedure can lengthen the soft palate, Z-plasty of the oral and nasal linings can restore the displaced levator veli palatini to their normal orientation.

Furlow [10] introduced the DOZ technique for cleft palate closure in 1986, and the benefit of restoring the levator sling and the proper anatomical structure made this approach popular. The use of $\mathrm{DOZ}$ avoids various airway problems caused by the pharyngeal flap procedure. Currently, it is generally accepted that patients with a cleft palate require palatoplasty at around 12 months after birth to ensure their normal linguistic development. Our present study evaluated the effects of DOZ on VPI after a primary palatoplasty. Although other reports have previously addressed the use of $\mathrm{DOZ}$ after other forms of palatoplasty $[11,12]$, this is the first report on the use of DOZ to correct VPI after a two-flap palatoplasty procedure.

\section{METHODS}

\section{Study design, patients, and settings}

A retrospective, time-series, observational study was designed. A chart review was performed for all of the patients who underwent palatoplasty for cleft palate repair in the Department of Plastic Surgery, Asan Medical Center, Seoul, Korea. All the operations were performed by the senior author (K.S.K.) between March 1999 and August 2005. Initially, we identified 188 patients who underwent palatoplasty for cleft palate repair. To focus our study on the patients treated for VPI using DOZ after primary two-flap palatoplasty, 106 patients who underwent primary palatoplasty using other methods (including DOZ and modified two-flap palatoplasty) were excluded. The patients with congenital syndrome or mental retardation were also excluded, owing to the possibility that they could have any other impediments that might affect their language capabilities; a total of 13 patients were included in the final study group.

The diagnosis of VPI was confirmed by intraoral examination, perceptual speech assessment, and nasendoscopy. Perceptual speech assessments were performed to evaluate articulation, nasal emission, and resonance. Speech assessments were performed by a single speech pathologist experienced in cleft speech. The patients were instructed to read out a standard piece of text, and were evaluated for resonance, nasal emission, and articulation. Resonance was stratified into six grades according to its severity (grade 1 , normal; grade 2 , mild; grade 3 , mild to moderate; grade 4, moderate; grade 5 , moderate to severe; grade 6 , severe). Descriptive statistics were generated, and ordinal logistic regression analysis of the change of hypernasality grades was performed. Flexible nasendoscopy was performed by the senior author. The velopharyngeal closure pattern and velum motion was recorded for each patient while they read out the standard text. The patients in the study cohort had a history of two-flap palatoplasty performed by the senior author (K.S.K.) at an average age of 12.2 months (range, 11 to 16 months). The average age of patients at the time of DOZ surgery was 5 years and 1 month (range, 3 years and 2 months to 6 years). The speech outcomes after DOZ were evaluated in an outpatient facility at an average of 8.3 months. The average follow-up period was 19.7 months (range, 4 to 44 months) (Table 1 ).

The velopharyngeal gap and velum length were measured by the surgeon in the operating room with a ruler before and right after surgery under general anesthesia. The relative location

\section{Table 1. Patient charateristics}

\begin{tabular}{|c|c|c|c|c|c|c|}
\hline Patient & Sex & Follow-up (mo) & Cleft type & $\begin{array}{c}\text { Age at primary } \\
\text { palatoplasty (mo) }\end{array}$ & Age at DOZ & Speech therapy \\
\hline 1 & $M$ & 15 & Palate only & 16 & $6 \mathrm{yr}$ & $\mathrm{O}$ \\
\hline 2 & $M$ & 8 & UCLP & 12 & $8 \mathrm{yr}$ & $\mathrm{O}$ \\
\hline 3 & M & 34 & BCLP & 13 & $6 \mathrm{yr}$ & $x$ \\
\hline 4 & $M$ & 44 & UCLP & 11 & 3 yr 6 mo & $\mathrm{O}$ \\
\hline 5 & $\mathrm{~F}$ & 8 & Palate only & 11 & 4 yr 8 mo & $\mathrm{O}$ \\
\hline 6 & $\mathrm{~F}$ & 8 & Palate only & 12 & $4 \mathrm{yr} 7 \mathrm{mo}$ & $\mathrm{O}$ \\
\hline 7 & $M$ & 27 & BCLP & 15 & $6 \mathrm{yr}$ & $\mathrm{O}$ \\
\hline 8 & M & 9 & UCLP & 11 & $6 \mathrm{yr}$ & $\mathrm{O}$ \\
\hline 9 & $\mathrm{~F}$ & 35 & UCLP & 11 & 3 yr 2 mo & $\mathrm{O}$ \\
\hline 10 & M & 4 & BCLP & 11 & 4 yr $8 \mathrm{mo}$ & $\mathrm{O}$ \\
\hline 11 & $\mathrm{~F}$ & 22 & UCLP & 11 & 4 yr 4 mo & $\mathrm{O}$ \\
\hline 12 & $M$ & 25 & UCLP & 11 & 4 yr 1 mo & $\mathrm{O}$ \\
\hline 13 & M & 17 & UCLP & 13 & 5 yr 6 mo & $\mathrm{O}$ \\
\hline
\end{tabular}


Fig. 1. Relative location change of the uvula to the adenoid

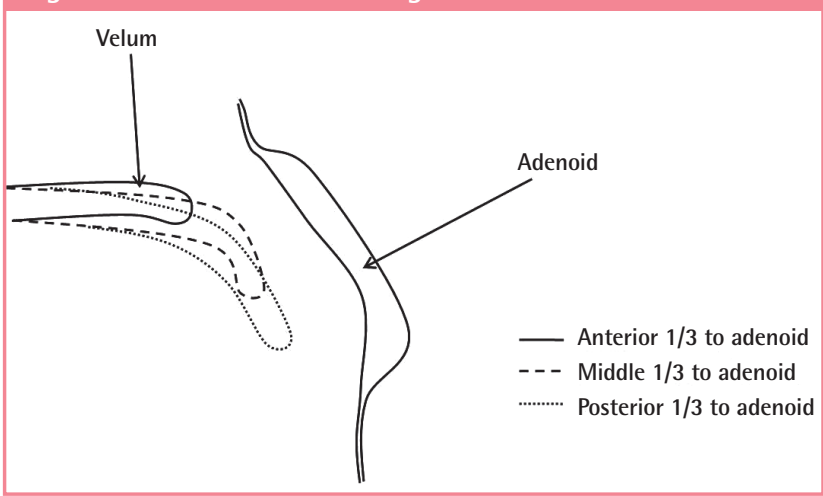

change of the uvula to the adenoid was also recorded (Fig. 1). All of the operations were performed by the same surgeon who had performed primary two-flap palatoplasty in all of the cases. The patients were observed in an outpatient facility, where a language assessment was performed. All the patients were offered therapy by the speech therapist. For social reasons, 12 of the 13 patients were able to receive speech therapy.

\section{Surgical technique}

The surgical technique used was similar to that of the original Furlow method, except that there was no incision at the uvula.

Fig. 2. Surgical techniques for double opposing Z-plasty in velopharyngeal insufficiency patients

( $A$, B) Preoperative design. (C, D) Elevation of the anterior-based mucosal flap. ( $E, F)$ Elevation of the posterior musculomucosal flap. $(\mathrm{G}, \mathrm{H})$ The muscle and mucosa were repaired.
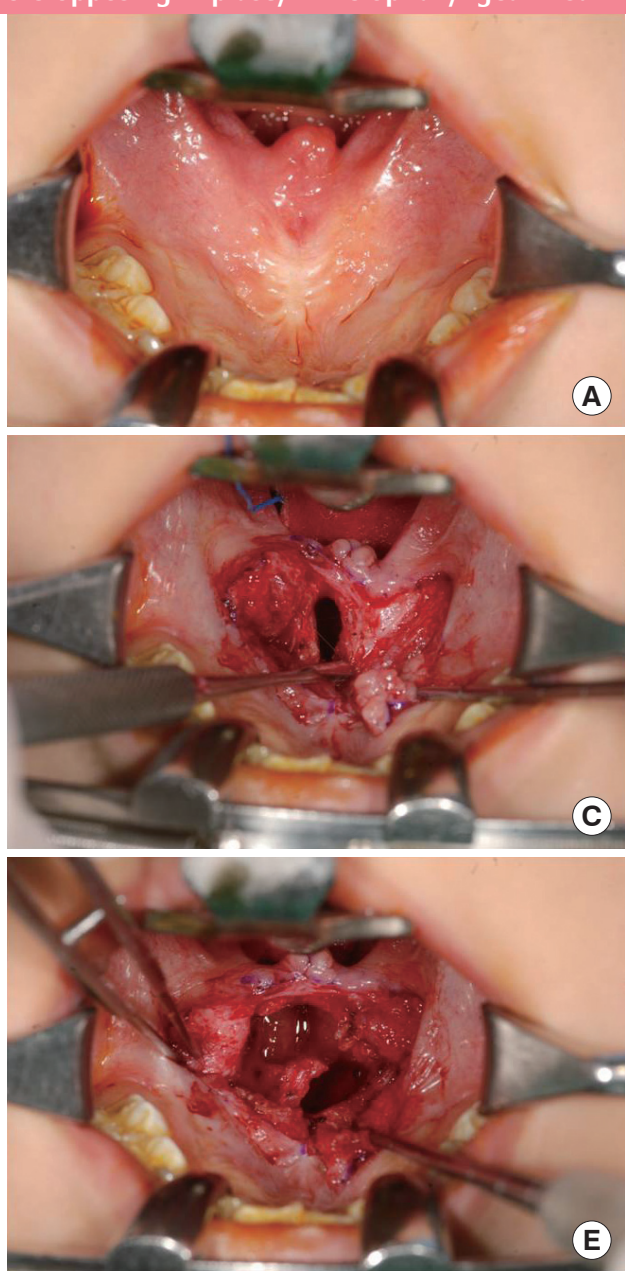

(E)
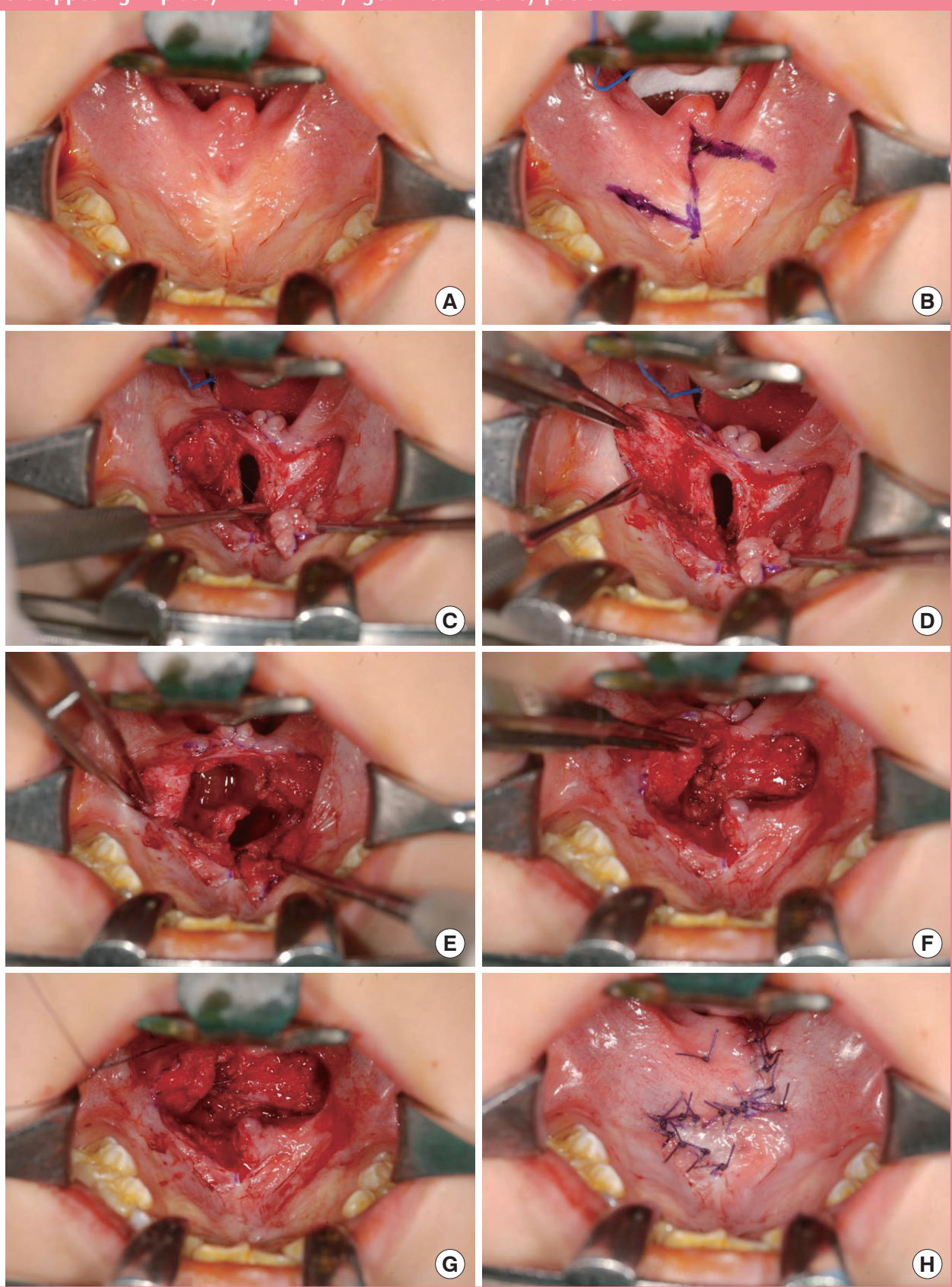
The anterior-based mucosal flap was designed on the right side of the soft palate, and the mucosal flaps were repositioned at an angle of between $70^{\circ}$ and $80^{\circ}$ relative to the midline axis. The lateral limb of the mucosal flap was extended to the end of the medial side of the maxillary tuberosity. The posterior musculomucosal flap was elevated from the left, leaving the nasal side mucosa intact. Scar tissue around the superior pharyngeal constrictor and the levator veli palatini muscle was released to ease the transverse rotation of the posterior flap. The levator veli palatini muscles with a sagittal orientation were thoroughly dissected, and the transverse muscle sling was repaired (Fig. 2).

\section{Statistical analysis}

The pre- and postoperative hypernasality grade was statistically analyzed using the Wilcoxon signed rank test.

\section{RESULTS}

All of the patients were discharged on the first day after surgery. No surgical complications such as postoperative bleeding, infection, flap necrosis, flap dehiscence, oronasal fistula, or airway problems were seen. Six patients $(6 / 13,46.1 \%)$ had normal language capabilities so that speech therapy could be terminated. The hypernasality grade was significantly improved $(\mathrm{P}=0.0015)$ after surgery in all of the patients (Fig. 3). After surgery, nasal emission disappeared in 8 patients (61.5\%), but persisted with reduced severity in 5 patients $(38.5 \%)$. Articulation was improved in all of the cases, albeit to different extents (Table 2).

Table 3 shows the change in the location of the uvula, which was measured by the relative location of the uvula to the adenoid and velopharyngeal gap (VP gap). The location of the uvula before surgery was at the middle third of the adenoid in $11 \mathrm{pa}-$ tients. After surgery, the uvula was on the posterior third of the adenoid in 4 cases, and on the posterior margin of the adenoid

\section{Fig. 3. Changes in the hypernasality grade $(P=0.0015)$}

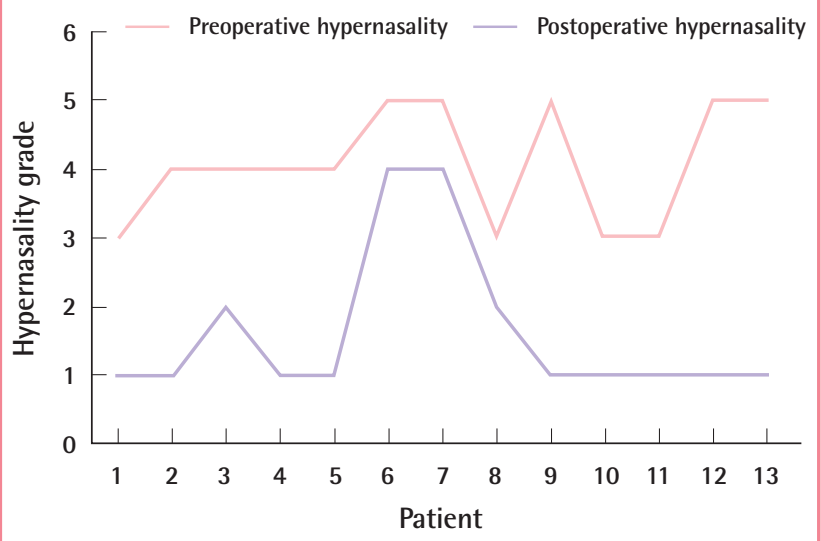

in 7 cases. In patient 10 and 11, the VP gap was also measured by a ruler. Whereas the VP gap decreased from 11.5 to $7 \mathrm{~mm}$ (60.9\% of the original length) for patient 10 , it decreased from 12.5 to $8 \mathrm{~mm}$ ( $64 \%$ of the original length) in patient 11 . The mean decrease was $4.5 \mathrm{~mm}$.

\section{DISCUSSION}

Velopharyngeal dysfunction is a generic term for any type-A abnormal velopharyngeal function regardless of etiology. Velopharyngeal dysfunction is divided into three groups based on etiology as follows: velopharyngeal insufficiency, velopharyngeal incompetence, and velopharyngeal mislearning. The term "velopharyngeal insufficiency" is used by Trost-Cardamone to refer to "any structural defect of the velum or pharyngeal wall at the level of the nasopharynx" [13]. There is either insufficient tissue to accomplish closure, or some kind of mechanical interference that prevents closure. Most often, these problems are congenital. Velopharyngeal incompetence includes neurogenic etiologies that result in impaired motor control or impaired motor programming of the velopharynx.

Velopharyngeal mislearning, the third category, includes etiologies that are not caused by structural defects or neuromotor pathologies of the velopharyngeal complex. The complexity of the terminology and potential causes of VPI underscore the importance of a thorough multispecialty evaluation and assessment before any therapeutic intervention is undertaken. This should include perceptual speech evaluation, pressure-flow measurements, nasopharyngeal endoscopy, and cinefluoroscopy.

Factors that determine the velopharyngeal function include the length and mobility of the soft palate, medial movement of the lateral pharyngeal wall, anterior movement of the pharyngeal wall, the presence of Passavant's ridge, and the thickness of

Table 2. Speech outcomes after double opposing Z-plasty

\begin{tabular}{|rcclc|}
\hline Patient & $\begin{array}{c}\text { Preoperative } \\
\text { hypernasality }\end{array}$ & $\begin{array}{c}\text { Postoperative } \\
\text { hypernasality }\end{array}$ & $\begin{array}{c}\text { Nasal } \\
\text { emission }\end{array}$ & Articulation \\
\hline 1 & 3 & 1 & Disappeared & Impoved \\
2 & 4 & 1 & Disappeared & Impoved \\
3 & 4 & 2 & Persistent & Impoved \\
4 & 4 & 1 & Disappeared & Impoved \\
5 & 4 & 1 & Disappeared & Impoved \\
6 & 5 & 4 & Persistent & Impoved \\
7 & 5 & 4 & Persistent & Impoved \\
8 & 3 & 2 & Persistent & Impoved \\
9 & 5 & 1 & Disappeared & Impoved \\
10 & 3 & 1 & Disappeared & Impoved \\
11 & 3 & 1 & Disappeared & Impoved \\
12 & 5 & 1 & Disappeared & Impoved \\
13 & 5 & 1 & Persistent & Impoved \\
\hline
\end{tabular}


Table 3. Changes in location of the uvula before and after surgery

\begin{tabular}{|c|c|c|c|c|}
\hline \multirow{2}{*}{ Patient } & \multicolumn{2}{|c|}{ Relative location of uvula to adenoid } & \multicolumn{2}{|c|}{ Velopharyngeal gap (mm) } \\
\hline & Preoperative & Postoperative & Preoperative & Postoperative \\
\hline 1 & Mid. $1 / 3$ to adenoid & Post. margin of adenoid & $(-)$ & $(-)$ \\
\hline 2 & Mid. $1 / 3$ to adenoid & Post. margin of adenoid & $(-)$ & $(-)$ \\
\hline 3 & Mid. $1 / 3$ to adenoid & Post. margin of adenoid & $(-)$ & $(-)$ \\
\hline 4 & Mid. 1/3 to adenoid & Post. margin of adenoid & $(-)$ & $(-)$ \\
\hline 5 & Mid. $1 / 3$ to adenoid & Post. $1 / 3$ to adenoid & $(-)$ & $(-)$ \\
\hline 6 & Mid. 1/3 to adenoid & Post. margin of adenoid & $(-)$ & $(-)$ \\
\hline 7 & Mid. $1 / 3$ to adenoid & Post. $1 / 3$ to adenoid & $(-)$ & $(-)$ \\
\hline 8 & Mid. $1 / 3$ to adenoid & Post. margin of adenoid & $(-)$ & $(-)$ \\
\hline 9 & Mid. $1 / 3$ to adenoid & Post. 1/3 to adenoid & $(-)$ & $(-)$ \\
\hline 10 & $(-)$ & $(-)$ & 11.5 & 7 \\
\hline 11 & $(-)$ & $(-)$ & 12.5 & 8 \\
\hline 12 & Mid. $1 / 3$ to adenoid & Post. margin of adenoid & $(-)$ & $(-)$ \\
\hline 13 & Mid. $1 / 3$ to adenoid & Post. $1 / 3$ to adenoid & $(-)$ & $(-)$ \\
\hline
\end{tabular}

the adenoid tissue. The use of DOZ to correct VPI enhances the mobility of the soft palate. The DOZ procedure adjusts the direction of the scar on the palate, thus withholding contraction and ensuring better maturation [11].

The DOZ technique further allows anatomic restoration, with rearrangement of the levator veli palatine muscles in the transverse position, to resemble the normal anatomy that forms stronger levator sling dynamics and a more mobile velum. Z-plasty lengthens the sagittal midline length of the soft palate at the nasal and oral side in both directions, as well as causing the lateral pharyngeal wall to gather closely by lengthening and narrowing [14]. Another merit of the $\mathrm{DOZ}$ procedure is that it prevents the maxilla from attaching to the posterior pharyngeal wall and assuming an abnormal structure, thereby theoretically avoiding any effects on facial development [12]. Furthermore, the DOZ method protects the pharyngeal musculature, which is closely related to velopharyngeal closure, and which, therefore, does not affect dynamic physiology [15]. Importantly, there is no risk of airway problems or disturbance of the physiology of the nasopharynx in patients at an early developmental age [11]. Our success with $\mathrm{DOZ}$ for primary repair of the cleft palate over the past 15 years has encouraged us to use the technique for secondary repair of VPI after primary two-flap palatoplasty.

The purpose of our present study was to assess the utility of DOZ for surgical correction of VPI in patients treated using primary palatoplasty with the two-flap technique. Randall et al. [16] have previously mentioned the use of DOZ as a secondary procedure but provided no detailed description. Later, Chen et al. [11] reported the effects of $\mathrm{DOZ}$ on the correction of secondary VPI in 18 cases, although, they did not describe the surgical choice of primary palatoplasty. The incidence of VPI after primary palatoplasty ranges from 5\% to 36\% [1]. Many authors have previously reported better results when both intravelar veloplasty (IVV) and either the von Langenbeck or the VeauWardill-Kilner methods were used $[17,18]$. However, the VeauWardill-Kilner pushback method lengthens palate in V-Y form by mucosal periosteum tissue. Any raw areas not covered by the mucosa contract and pull the velum forward, thereby shortening it. Furthermore, the method may cause defective maxilla development and dental interlocking [19].

Deren et al. [12] have shown comparable results for the application of DOZ to correct secondary VPI after primary palatoplasty with the Veau-Wardill-Kilner pushback method. Notably, they observed that using DOZ for VPI after the Veau-WardillKilner pushback procedure provided duplicative lengthening of the palate in two operations, although, as we mentioned above, maxilla development is inevitably limited by the Veau-WardillKilner pushback procedure. In our current study, we have identified an effective way to use the $\mathrm{DOZ}$ method to lengthen the palate in instances where VPI has occurred after performing the two-flap procedure for primary palatoplasty to minimize fibrotic scarring and insufficient maxilla development. We performed primary palatoplasty by combining two-flap palatoplasty and IVV. Repositioning of the levator muscle is important for speech improvement after primary palatoplasty [10]. We combined IVV when performing primary palatoplasty but re-explored and reinforced the levator muscle with $\mathrm{DOZ}$ when a correction of VPI was required.

The influence of the preoperative VP gap on the DOZ surgical outcomes in VPI patients remains controversial. Chen et al. [11] reported 16 cases of velopharyngeal closure using DOZ in 18 patients. According to their analysis, good results were 
expected in the patients with a VP gap of less than $5 \mathrm{~mm}$, although unacceptable results were found in patients with a VP gap length larger than $10 \mathrm{~mm}$. On the other hand, Lindsey and Davis [20] reported successful results in 7 of 8 patients $(87.5 \%)$ with VP gaps that ranged in size from 6 to $8 \mathrm{~mm}$. Hudson et al. [21] recommended performing DOZ initially for VPI of all grades. Sie and Gruss [22] have suggested that the VP gap size is not a significant determinant of the outcome of DOZ. In our current study, an obvious improvement in the hypernasality grade (improvement from grade 3 to grade 1), extent of nasal emission, and articulation were noted in 2 patients with VP gaps larger than $11 \mathrm{~mm}[11]$. The differences between the reports may be due to the differences in the techniques used by the surgeons. We designed the central limb of ' $Z$ ' to be longer than usual, which enabled the soft palate to be lengthened and permitted a more effective rearrangement of the levator veli palatini muscle. However, the number of patients in the other series was too small to permit clear conclusions [23]. We propose that the efficacy of DOZ is unpredictable in patients with severe VPI, although more extensive, prospective studies are needed.

In general, secondary DOZ is not indicated for patients who have undergone primary $\mathrm{DOZ}$ for cleft palate repair, because it can damage newly formed muscle. Nonetheless, in our study series, we found one patient who showed improved speech after the use of DOZ to correct VPI, after undergoing primary repair of a cleft palate with DOZ. Although this patient was excluded from our final analysis because of an accompanying congenital syndrome, this observation emphasizes the necessity for larger, prospective studies on the effectiveness of DOZ 'after $\mathrm{DOZ}$ for primary cleft palate repair'.

The rate of oronasal fistulas has been reported to range from $5 \%$ to $10 \%$ after primary DOZ $[24,25]$. However, as in other series $[20,21]$, no oronasal fistula after secondary DOZ was observed in our study cohort. The reason the oronasal fistula rate was lower in the secondary cases than in the primary cases is unknown, but we speculate that the absence of a midline defect in the secondary cases minimizes the tension, thereby decreasing the incidence of complications [12].

Our present study aimed to provide guidelines for the application of DOZ to lengthen the palate when VPI occurs after primary palatoplasty using the two-flap technique, because this intervention minimizes the limitation of maxilla development. Advantages of $\mathrm{DOZ}$ compared with other surgical options for VPI correction include short surgery time, fewer severe complications, and no harmful effects against pharyngeal function. The results of our current study indicate that $\mathrm{DOZ}$ is a promising initial choice for surgical treatment for VPI in patients who have undergone two-flap palatoplasty for cleft palate repair.

\section{REFERENCES}

1. Bardach J, Morris HL. Multidisciplinary management of cleft lip and palate. Philadelphia: Saunder; 1990.

2. Wyatt R, Sell D, Russell J, et al. Cleft palate speech dissected: a review of current knowledge and analysis. Br J Plast Surg 1996;49:143-9.

3. Sloan GM. Posterior pharyngeal flap and sphincter pharyngoplasty: the state of the art. Cleft Palate Craniofac J 2000; 37:112-22.

4. Witt PD, O'Daniel TG, Marsh JL, et al. Surgical management of velopharyngeal dysfunction: outcome analysis of autogenous posterior pharyngeal wall augmentation. Plast Reconstr Surg 1997;99:1287-96.

5. Peat BG, Albery EH, Jones K, et al. Tailoring velopharyngeal surgery: the influence of etiology and type of operation. Plast Reconstr Surg 1994;93:948-53.

6. Pensler JM, Bauer BS. Levator repositioning and palatal lengthening for submucous clefts. Plast Reconstr Surg 1988; 82:765-9.

7. Kravath RE, Pollak CP, Borowiecki B, et al. Obstructive sleep apnea and death associated with surgical correction of velopharyngeal incompetence.J Pediatr 1980;96:645-8.

8. Shprintzen RJ. Pharyngeal flap surgery and the pediatric upper airway. Int Anesthesiol Clin 1988;26:79-88.

9. Orr WC, Levine NS, Buchanan RT. Effect of cleft palate repair and pharyngeal flap surgery on upper airway obstruction during sleep. Plast Reconstr Surg 1987;80:226-32.

10. Furlow LT Jr. Cleft palate repair by double opposing Z-plasty. Plast Reconstr Surg 1986;78:724-38.

11. Chen PK, Wu JT, Chen YR, et al. Correction of secondary velopharyngeal insufficiency in cleft palate patients with the Furlow palatoplasty. Plast Reconstr Surg 1994;94:933-41.

12. Deren O, Ayhan M, Tuncel A, et al. The correction of velopharyngeal insufficiency by Furlow palatoplasty in patients older than 3 years undergoing Veau-Wardill-Kilner palatoplasty: a prospective clinical study. Plast Reconstr Surg 2005; 116:85-93.

13. Trost-Cardamone JE. Coming to terms with VPI: a response to Loney and Bloem. Cleft Palate J 1989;26:68-70.

14. Furnas DW, Fischer GW. The Z-plasty: biomechanics and mathematics. Br J Plast Surg 1971;24:144-60.

15. Witt PD, D’Antonio LL. Velopharyngeal insufficiency and secondary palatal management: a new look at an old problem. Clin Plast Surg 1993;20:707-21.

16. Randall P, LaRossa D, Solomon M, et al. Experience with the Furlow double-reversing Z-plasty for cleft palate repair. Plast Reconstr Surg 1986;77:569-76. 
17. Dreyer TM, Trier WC. A comparison of palatoplasty techniques. Cleft Palate J 1984;21:251-3.

18. Hartel J, Gundlach KK, Ruickoldt K. Incidence of velopharyngoplasty following various techniques of palatoplasty. J Craniomaxillofac Surg 1994;22:272-5.

19. Brardach J, Salyer K. Surgical techniques in cleft lip and palate. Chicago: Mosby Year Book; 1987.

20. Lindsey WH, Davis PT. Correction of velopharyngeal insufficiency with furlow palatoplasty. Arch Otolaryngol Head Neck Surg 1996;122:881-4.

21. Hudson DA, Grobbelaar AO, Fernandes DB, et al. Treatment of velopharyngeal incompetence by the Furlow Z-plasty. Ann Plast Surg 1995;34:23-6.

22. Sie KC, Gruss JS. Results with Furlow palatoplasty in the management of velopharyngeal insufficiency. Plast Reconstr Surg 2002;109:2588-9.

23. Dailey SA, Karnell MP, Karnell LH, et al. Comparison of resonance outcomes after pharyngeal flap and furlow doubleopposing z-plasty for surgical management of velopharyngeal incompetence. Cleft Palate Craniofac J 2006;43:38-43.

24. Mann EA, Sidman JD. Results of cleft palate repair with the double-reverse Z-plasty performed by residents. Otolaryngol Head Neck Surg 1994;111:76-80.

25. Brothers DB, Dalston RW, Peterson HD, et al. Comparison of the Furlow double-opposing Z-palatoplasty with the WardillKilner procedure for isolated clefts of the soft palate. Plast Reconstr Surg 1995;95:969-77. 